\title{
EFFECTS OF INTRAUTERINE COPPER WIRE ON BLASTOCYST AND UTERINE LYSOSOMES OF THE RABBIT: A CYTOCHEMICAL AND ULTRASTRUCTURAL STUDY
}

\author{
R. ABRAHAM, R. MANKES, J. FULFS, L. GOLBERG AND \\ F. COULSTON \\ Institute of Experimental Pathology and Toxicology, \\ Albany Medical College, Albany, New York 12208, U.S.A.
}

(Received 4th Fanuary 1973)

Summary. Following the insertion of copper wire into their uterine horns, rabbits were mated and cytochemical and ultrastructural observations carried out on blastocysts and on the left (control) and right (treated) horns of the pregnant uteri. The blastocysts and uterine tissue from the control horns were normal in all respects. Blastocysts obtained from the treated horns on Day 6 of gestation contained numerous membrane-bound vacuoles, identified as lysosomes by acid-phosphatase staining, that contained amorphous material in which the presence of copper was revealed by the rubeanic acid procedure. No blastocysts were recovered from treated horns after Day 6.

Significant changes were observed in lysosomes of uterine epithelial cells on Days 6 to 10 of gestation. The effects were localized to the segment of uterus containing the copper wire and involved uptake of copper, autophagy, formation of myeloid bodies and shedding of epithelial cells containing such structures into the uterine lumen.

There was evidence to suggest that the entry of copper into blastocyst lysosomes was followed by release of lysosomal enzymes, cellular autolysis and death of the affected cells. In the uterus, the toxic effects of copper appeared to be confined to the epithelial cells, whose detachment from the mucosal surface may constitute a protective mechanism. The early effect of copper on the blastocyst suggests that this is the primary site of action of the metal.

\section{INTRODUCTION}

In a study of the process of implantation in the rabbit (Abraham, Hendy, Dougherty, Fulfs \& Golberg, 1970), the objective was to examine the interaction between blastocyst and uterine epithelial cells, with particular emphasis on the distribution and functional changes in lysosomal enzymes in the two cell types before and during implantation. No remarkable changes were found in the lysosomes of the blastocyst, but those of the uterine epithelial cells exhibited 
a series of striking structural alterations believed to represent responses to the presence and attachment of the blastocyst.

In order to examine the rôle of lysosomes in conditions involving interference with implantation, a copolymer of mixed phenylmethylcyclosiloxanes was chosen. Previous studies had shown that this material, when given to rabbits on Days 4 and 5 of pregnancy, prevented implantation (LeFevre, Coulston \& Golberg, 1972). In contrast to the meagre number of lysosomes seen in normal blastocysts, those blastocysts recovered from siloxane-treated does on Day 6 were found to contain large lysosomal aggregates. On the other hand, lysosomes in the uterine mucosa on Days 6 to 11 remained unaffected, an event associated with the integrity of the uterine tissues. A primary cytotoxic action of the polymeric siloxanes on the blastocyst was postulated (Abraham, Fulfs, Golberg \& Coulston, 1973).

Like other heavy metals, copper is known to be localized in renal and hepatic lysosomes (Koenig, 1963; Goldfischer, 1965). The toxic effects of such metals are thought to be mediated, at least in part, through the action of the metals on lysosomes (Lindquist, 1968). Copper has proved useful as an intrauterine contraceptive device in rabbits (Zipper, Medel \& Prager, 1969), rats and hamsters (Chang, Tatum \& Kincl, 1970) and women (Zipper, Medel, Pastene, Rivera \& Tatum, 1970; Newton, Elias \& McEwan, 1972), but its mode of action remains controversial. The present investigation was undertaken to ascertain the action of copper on uterine and blastocyst lysosomes in an effort to clarify one possible mechanism by which intrauterine contraceptive action is brought about by this metal.

\section{MATERIALS AND METHODS}

Female New Zealand rabbits ( 3.5 to $4.5 \mathrm{~kg}$ ) were used in this study. The procedure was essentially that described by Zipper et al. (1969). Under ether anaesthesia and by abdominal incision, four copper wires, each of $0.25 \mathrm{~mm}$ diameter and $1.5 \mathrm{~cm}$ long (twisted), were inserted in the lower portion of the right uterine horn close to the cervix and fastened by a silk suture to prevent their expulsion.

Following insertion of the copper wires, the animals were allotted to two groups. Eleven rabbits were killed by overdoses of pentobarbitone 3, 6 and 8 days after the operation. Pieces of the right uterus were taken around and distal to the copper wires; tissue was also taken from corresponding areas of the left horn. The second group of twelve rabbits was allowed to rest for 8 days and then mated. Specimens of uterus were taken on Days 3, 6, 8 and 10; in addition, blastocysts were collected on Day 6. No blastocysts were recovered on Day 8 or Day 10. Implantation sites were not observed in the right uterine horns but were present in the left horns, and the latter served as controls.

Whole blastocysts and uteri were fixed in formol-calcium (18 to $24 \mathrm{hr}$ ) and transferred to gum sucrose. Sections ( $8 \mu \mathrm{m}$ thick) of the uteri cut on a freezing microtome, along with whole blastocysts, were stained by the methods of Gomori (1952) and Barka \& Anderson (1962). Sections (0.5 to $1.0 \mu \mathrm{m}$ thick) of uterine and blastocyst tissue, embedded in Epon, were either stained directly with 
Paragon multiple stain (CPC), or by the rubeanic acid method of Uzman (1956) for copper

For electronmicroscopy, whole blastocysts and small blocks of uterine tissue were fixed for $2 \mathrm{hr}$ in $2.5 \%$ glutaraldehyde made up in $0.1 \%$ Sorensen phosphate buffer, $\mathrm{pH} 7 \cdot 4$, post-fixed in $\mathrm{OsO}_{4}$, rapidly dehydrated in alcohol, blockstained with uranyl nitrate and lead acetate, and embedded in Epon 812. Acid phosphatase activity was demonstrated by the method of Holt \& Hicks (1961) in frozen sections ( $40 \mu \mathrm{m}$ thick) of uterine blocks fixed in formol-calcium. The sections were post-fixed in $\mathrm{OsO}_{4}$ and prepared as described above. Sections $2 \mu \mathrm{m}$ thick were stained with toluidine blue and representative areas were chosen. Thin sections from these areas were examined in an RCA EMU4 electron microscope.

\section{RESULTS}

\section{Light microscopy of 6-day-old blastocyst}

Blastocysts were obtained from both the normal and copper-containing horns. Those derived from the untreated horn were normal in all respects. Those from the copper-containing horns had numerous vacuoles containing opaque material in the cells of both the inner cell mass and the trophoblast (P1. 1, Fig. 1). The contents of these vacuoles gave a positive reaction for copper (Pl. 1, Fig. 2) by the method of Uzman (1956). Some of the embryonic cells were degenerate, staining lightly with toluidine blue or Paragon, and displaying either pycnotic or abnormal nuclei (Pl. 1, Fig. 1).

\section{Electronmicroscopy of 6-day-old blastocyst}

Adequate accounts are available in the literature describing the fine structure of the rabbit blastocyst (Enders, 1971). Blastocysts obtained from the left horns appeared normal in every respect.

Blastocysts derived from the copper-bearing right horns displayed nuclei with unusual chromatin patterns, or appeared to be undergoing degeneration (Pl. 1, Fig. 3a). Numerous membrane-bound vacuoles were observed that contained amorphous or fibrillar material (Pl. 1, Fig. 3b), membranous inclusions (Pl. 2, Fig. 4), or electron-dense crystalline material (Pl. 2, Fig. 5). Acid phosphatase reaction product was localized in some of these vacuoles identifying them as lysosomes. Residual bodies were not reactive to acid phosphatase staining (Pl. 2, Fig. 6).

\section{Light microscopy of uterus}

During Days 3 to 8 after insertion of copper wire, lysosomes, as visualized by their acid phosphatase staining, were present in the supra-nuclear regions of epithelial cells (Pl. 2, Fig. 7) very similar to those observed in the normal uterus (Abraham et al., 1970). Marked alterations in uterine lysosomes confined to areas proximal to the copper wire were first observed on Day 6 of gestation. Enhanced acid phosphatase activity was accompanied by an increase in the size and number of lysosomes (Pl. 2, Fig. 8); the effect became more pronounced on Day 8 of gestation, when small and large aggregates of lysosomes were often 
seen. In some instances, diffuse acid phosphatase staining occurred in the cytoplasm of the epithelial cells.

Examination of epoxy-embedded sections revealed that the epithelial cells had undergone degeneration and that some were sloughing off into the uterine lumen (Pl. 3, Fig. 9). In the distal region of the uterus $(3 \mathrm{~cm}$ away from the end of the copper wire), minimal changes were observed (P1. 3, Fig. 10). On Day 6 of gestation, there was an interesting rearrangement of the lysosomes to an entirely infranuclear position (Pl. 3, Fig. 11), similar to that observed during normal implantation. In contrast to the normal course of events, these changes in lysosomal distribution persisted to Day 8 of gestation.

\section{EXPLANATION OF PLATES 1 TO 5}

\section{PLATE 1}

FIGs 1 to 3. Rabbit blastocysts (6 days old) obtained from uteri containing a copper wire. Fig. 1. Epoxy-embedded section stained with Paragon. Many cells with vacuoles (arrows) contain opaque material and pycnotic nuclei (double arrows). $\mathrm{ZP}=$ Zona pellucida. $\times 460$.

Fig. 2. Epoxy-embedded section stained by Uzman's 'rubeanic acid' method shows brown inclusions (copper) in blastocyst cells (arrows). $\mathrm{ZP}=$ Zona pellucida. $\times 460$.

FIG. 3(a). Electronmicrograph of a damaged cell demonstrating a necrotic nucleus. $\times 3660$.

FIG. 3(b). Electronmicrograph of a portion of the blastocyst, demonstrating numerous vacuoles containing amorphous material (copper) in their cytoplasm. $\mathrm{N}=$ Nucleus. $\times 6600$.

\section{PLATE 2}

FIGs 4 to 6. Electronmicrograph of 6-day old rabbit blastocysts obtained from a coppercontaining uterus.

Fig. 4. Note numerous lysosomes with membranous inclusions (myeloid bodies) in the cytoplasm of the blastocyst. $\mathrm{V}=$ Microvilli. $\times 8100$.

Fig. 5. Portion of a blastocyst showing a group of lysosomes containing electron-dense crystalline material (copper). $\times 18,450$.

Fig. 6. Electronmicrograph demonstrating acid phosphatase activity in lysosomes. Note absence of enzyme activity in one of the lysosomes (arrow) that represents a myeloid body. $\times 13,500$.

FIGs 7 and 8 . Sections of rabbit uteri containing the copper wire and incubated for acid phosphatase activity.

Fig. 7. A 3-day uterus showing normal distribution of lysosomes in epithelial cells. $\times 460$.

Fig. 8. Note the dramatic increase in the size, number and enzyme activity of lysosomes seen at Day 8 in the uterus. The arrow points to a detached epithelial cell. $\times 460$.

\section{PLATE 3}

Figs 9 and 10. Epoxy-embedded, Paragon-stained sections of rabbit uteri obtained from the right horn on Day 8 of gestation.

FIg. 9. Section of uterus obtained from an area close to the copper wire, shows normal and degenerate epithelial cells, some of the latter lying free in the uterine lumen and others in the process of detachment. $\times 460$.

Fig. 10. In contrast to Fig. 9, this photomicrograph of the uterus appears normal, and was obtained from a region 2 to $3 \mathrm{~cm}$ away from the copper wire. $\times 460$.

Frg. 11. Similar to Fig. 10, but incubated for acid phosphatase activity. Note the distinct infranuclear position of lysosomes. $\times 460$.

Fras 12 and 13. Epon-embedded sections of an 8-day uterus (right horn), stained by the rubeanic acid method of Uzman (1956). Note the distribution of copper in the form of granules and as aggregates, particularly in epithelial cells lying free in the lumen or in the process of detachment. $\times 460$. 
PLAITE I

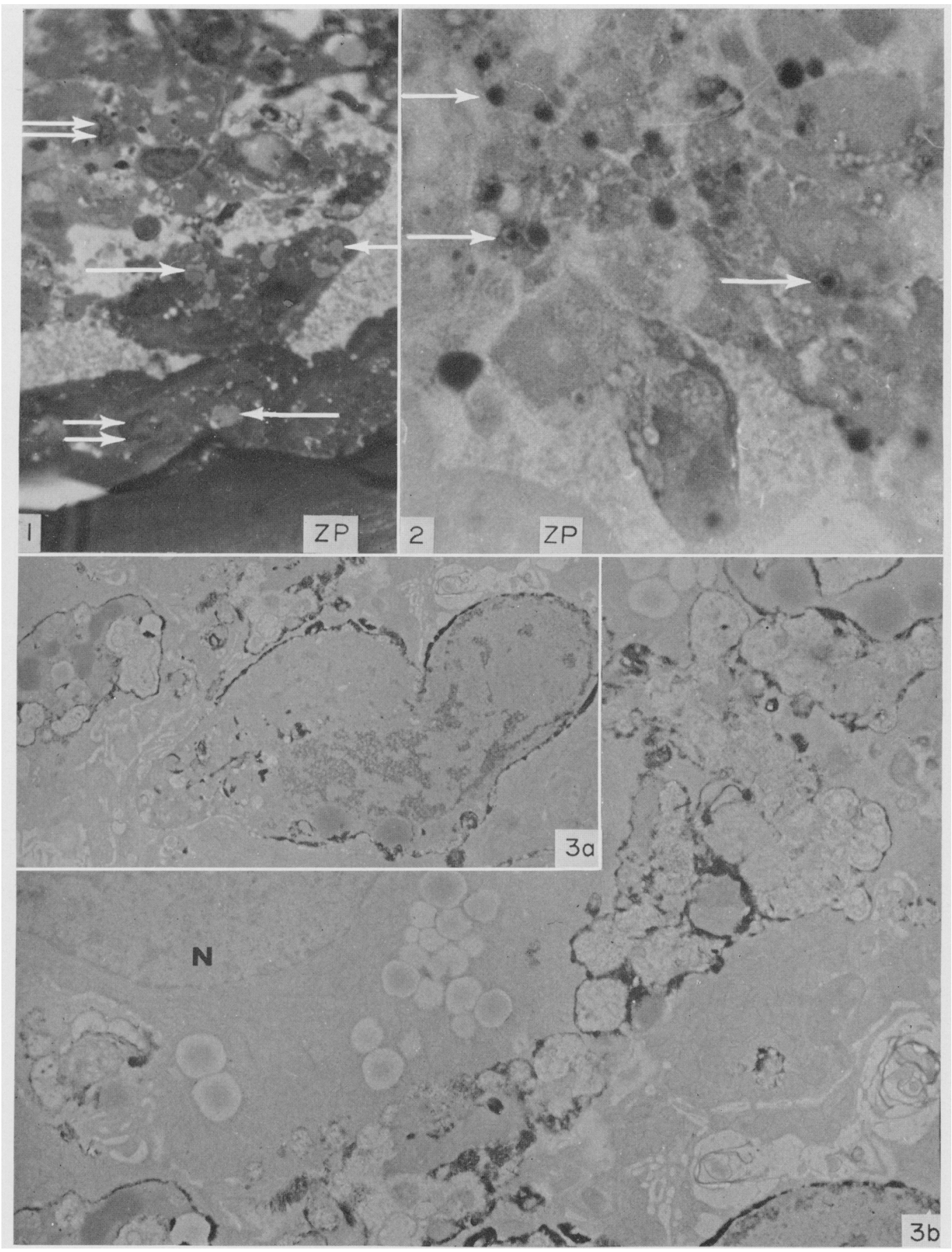


PLATE 2
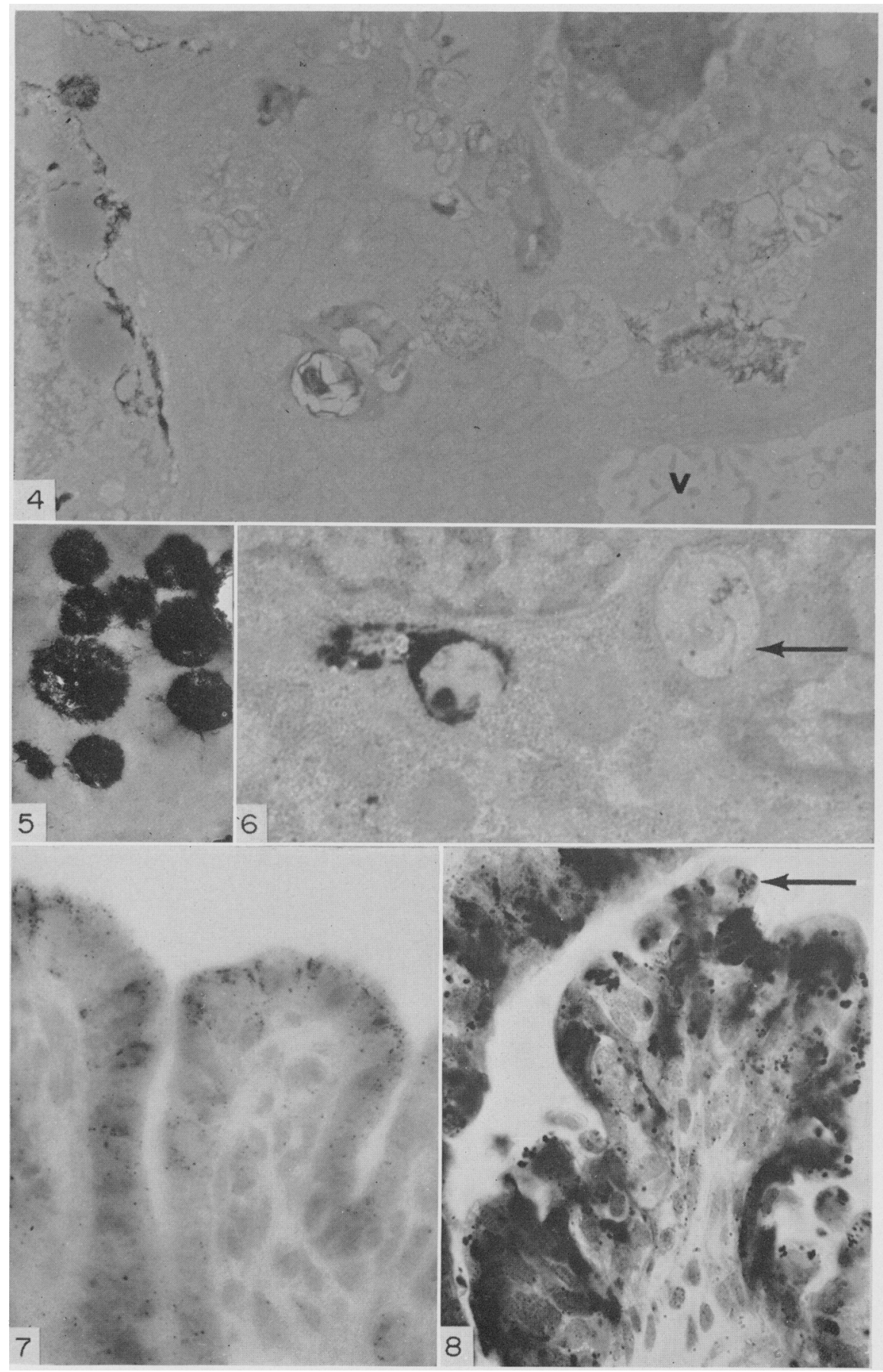
PL.A'TE 3

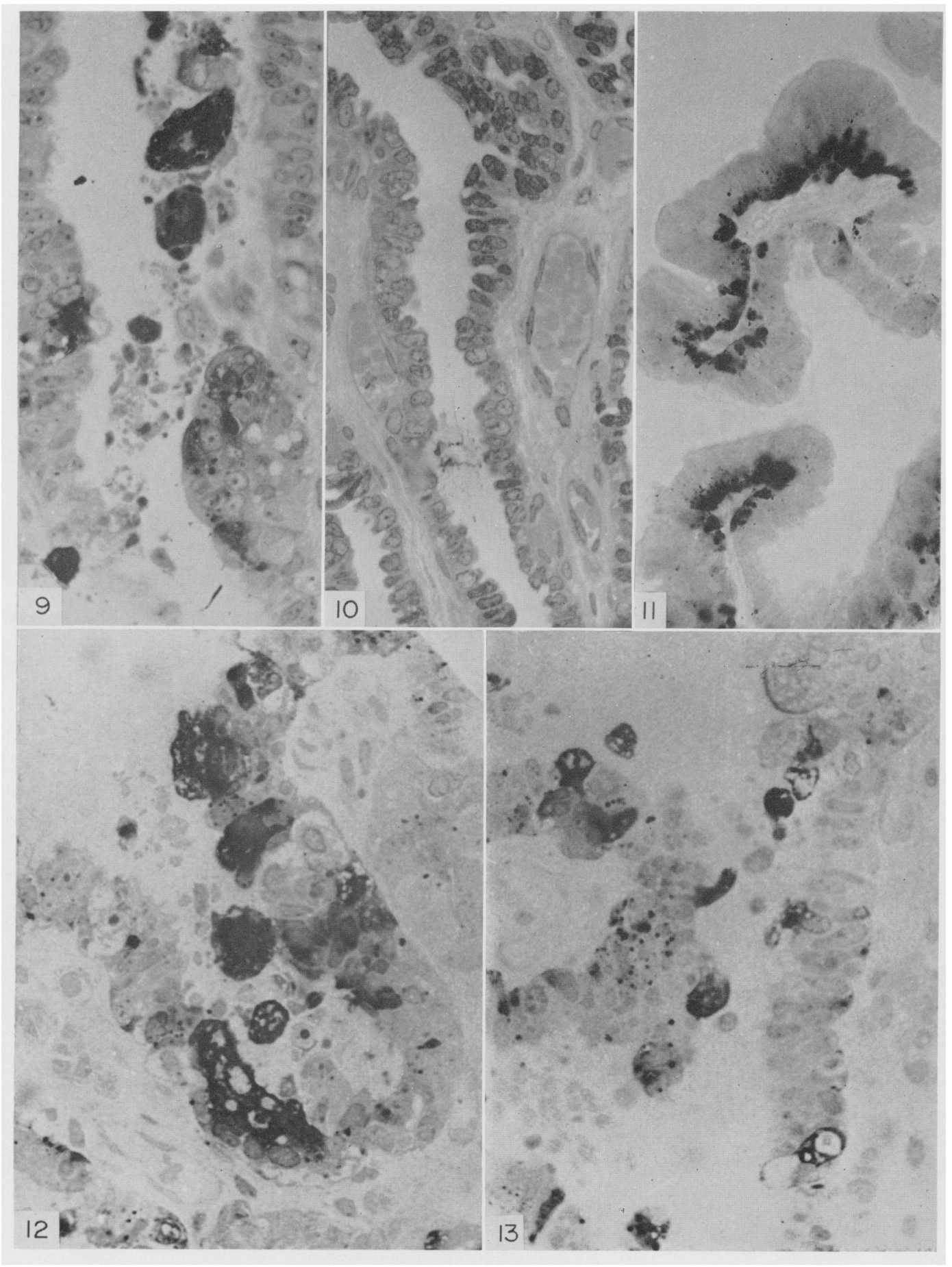


PI.ATE 4

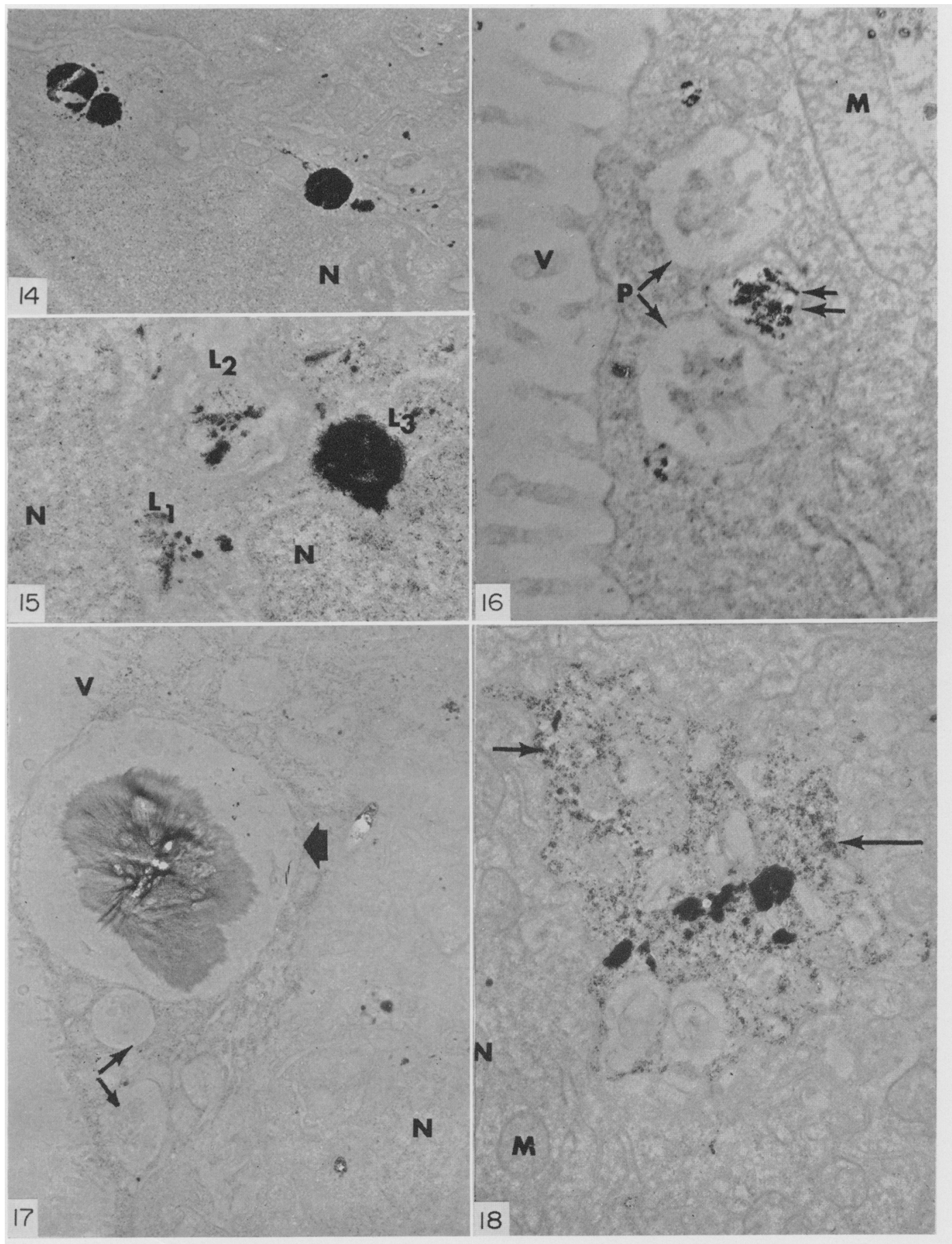




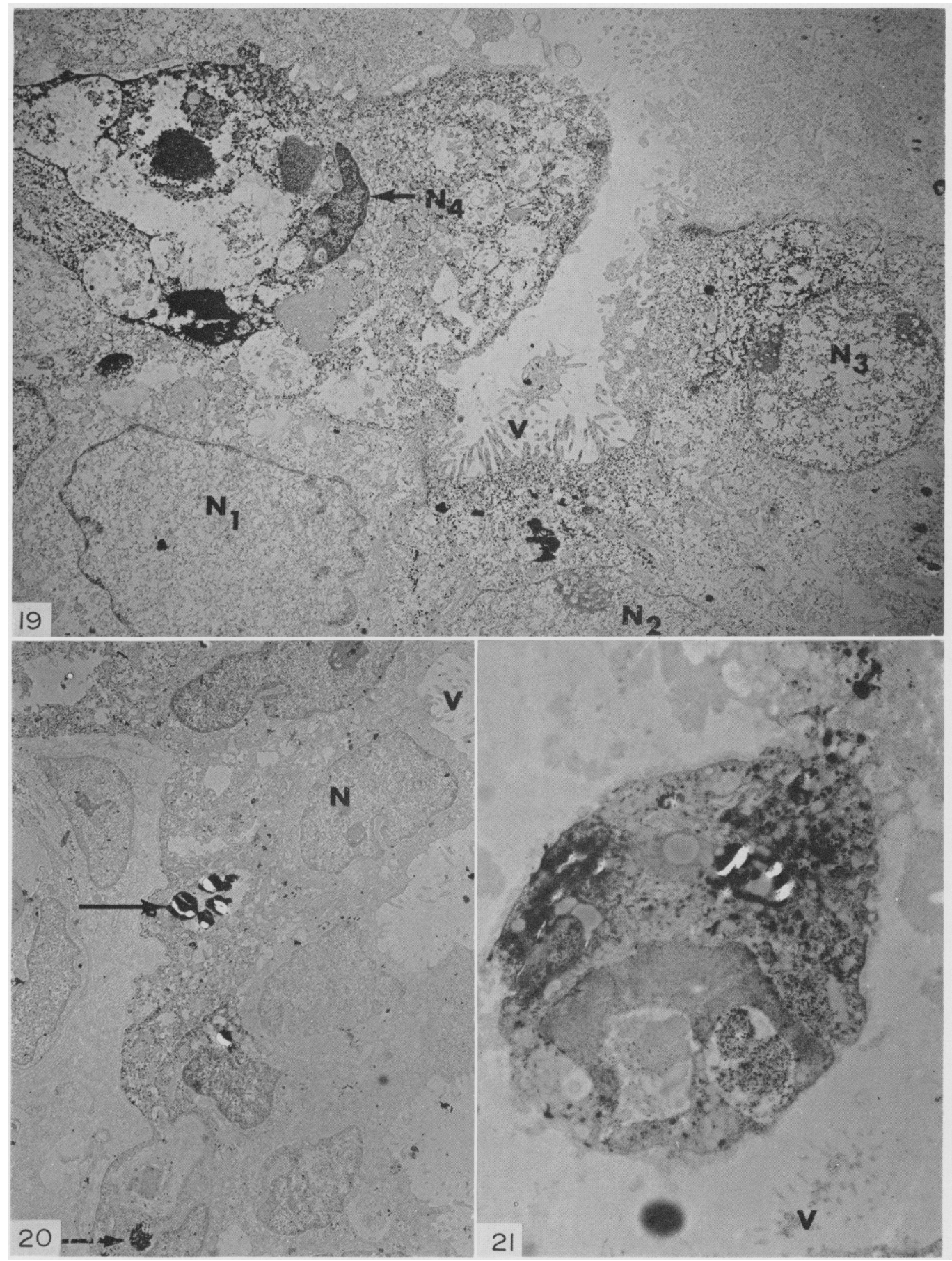


Histochemical staining for copper of the uteri obtained at different stages before and during gestation revealed a positive reaction for copper only on Day 8 of gestation (Pl. 3, Figs 12 and 13). Small granules and large accumulations of copper were noted, in degenerating cells as well as in those lying free in the uterine lumen. Proliferation of the mucosal stroma was present in some cases, but leucocytic infiltration was negligible.

\section{Electronmicroscopy of uterus}

Epithelial cells of the non-pregnant uterus contain very few lysosomes, which are usually supranuclear in position. On Day 6 of gestation, membranous fragments are observed in lysosomes representing autophagy by these organelles (Abraham et al., 1970). Copper has no obvious effect on the structure of the uterus in non-pregnant does, nor during the 3 days following mating. When uterine tissue was examined on Day 6 of gestation, dramatic alterations in lysosomes were a striking feature (Pl. 4, Figs 14 to 18). Various types of lysosomes appeared: primary lysosomes, homogeneous and intensely stained (Pl. 4, Fig. 14); phagosomes that showed no acid phosphatase staining but contained amorphous or fibrillar material (PI. 4, Figs 16 and 17); secondary lysosomes (phagolysosomes) that contained both fibrillar material and enzyme reaction product (Pl. 4, Figs 15 to 17), and myeloid bodies, structures containing degenerate membranes, mitochondria and cellular debris (Pl. 4, Fig. 18).

Degenerating epithelial cells with abnormal nuclei and many cytoplasmic inclusions derived from lysosomes were observed during Days 8 to 10 of gestation (P1. 5, Figs 19 and 20). Some of these cells were found in the uterine lumen

\section{PLATE 4}

Figs 14 to 18. Electronmicrographs of epithelial cells obtained from a 6-day rabbit uterus (right horn) and processed for acid phosphatase activity as indicated in the text. $\mathrm{N}=$ Nucleus; $\mathrm{M}=$ Mitochondria; $\mathrm{V}=$ Microvilli.

Fig. 14. Primary lysosomes displaying strong acid phosphatase activity in uterine epithelial cells. $\times 9160$.

FIG. 15. This electronmicrograph demonstrates secondary lysosomes (phagolysosomes) $\left(\mathrm{L}_{1}-\mathrm{L}_{3}\right)$ that contain crystalline material (copper) and acid phosphatase activity. $\times 26,560$.

FIG. 16. This portion of a uterus displays two phagosomes $(P)$ that contain amorphous material (copper) but no enzyme activity. A primary lysosome (double arrows) is in the process of fusing with the phagosomes. $\times 14,660$.

FIG. 17. This electromicrograph illustrates a phagolysosome (arrow head) that contains copper and acid phosphatase activity, as well as smaller phagosomes (arrows). $\times 6870$.

FIG. 18. This electronmicrograph demonstrates a large myeloid body containing membranes derived from unrecognizable structures and enzyme activity (arrows). × 26,560.

\section{PLATE 5}

Figs 19 to 21. Electronmicrographs of uterine material obtained from the right horn of rabbit uteri on Day $\mathbf{8}$ of gestation, and processed for acid phosphatase activity.

FIG. 19. Note necrotic nucleus $\left(\mathbf{N}_{\mathbf{4}}\right)$ and diffuse acid phosphatase activity in the cytoplasm of this cell. Gell $\mathrm{N}_{1}$ appears normal, but $\mathrm{N}_{2}$ and $\mathrm{N}_{3}$ are in the process of disintegration. Compare with Figs 12 and 13. $\times 3660$.

Fig. 20. Lysosomal changes in a predominantly infranuclear position were observed that usually (arrow) preceded epithelial cell detachment. $\times 3300$.

Fig. 21. A necrotic cell in the uterine lumen. Note the large aggregate of lysosomes that contain appreciable amounts of stainable copper. Compare with Figs 12 and 13. $\times 4120$. 
(P1. 5, Fig. 21). It was noticed that such cells contained considerable acid phosphatase staining both in lysosomes and non-lysosomal sites.

\section{DISCUSSION}

Uptake of copper by blastocyst lysosomes and its consequences

Whatever the mode of action of copper in bringing about intrauterine contraception, it is clear from our experiments that striking alterations occur in the blastocyst, with the formation of membrane-bound vacuoles (lysosomes) containing large accumulations of amorphous material, in which the presence of copper is demonstrable by the rubeanic acid reaction.

Ferm (1971) has recently reviewed investigations into the permeability of the blastocyst to teratogenic agents. Although studies have been made on the effects of azo dyes, viruses, antimetabolites, growth inhibitors and irradiation on the blastocyst, little is known about the action of specific heavy metals such as lead, cadmium, arsenic or mercury on the implanting blastocyst. The results reported here illustrate for the first time the uptake of copper by the rabbit blastocyst. The numerous copper-bearing lysosomes and autophagic vacuoles formed in the blastocyst are similar to those seen in the liver (Lindquist, 1968) and indicate a general stimulation of the lysosomal system in response to uptake of ionic copper into these organelles within the blastocyst. It seems reasonable to believe that overloading of lysosomes by copper initiates release of acid hydrolases into the cytoplasm, causing necrosis of numerous cells and loss of viability, with eventual disintegration of the blastocyst.

The localization of copper in hepatic lysosomes is well known through work in experimental animals (Verity, Gambell, Reith \& Brown, 1967; Lindquist, 1968; McNatt, Campbell \& Callahan, 1971) and studies in patients with Wilson's disease (Goldfischer, 1965). According to Goldfischer \& Sternlieb (1968), segregation of the metal in lysosomes initially protects the rest of the cell from copper toxicity, but excessive accumulation permits release into the cell cytoplasm, where the metal binds with sulphydryl-rich proteins and causes structural and metabolic changes. However, there is evidence that copper exercises direct effects on lysosomes, producing a marked increase of three lysosomal hydrolases in vivo: $\beta$-glucuronidase, acid phosphohydrolase, and $\mathrm{N}$ acetyl- $\beta$-D-glucosaminidase (Verity et al., 1967). Copper also releases acid phosphatase from lysosomes following exposure in vitro and increases appreciably the activities of non-sedimentable (unbound) sulphatase, acid phosphatase and cathepsin. A possible mechanism for the cytotoxic action of copper may be the initiation of cell damage by lipid peroxidation of, and damage to, lysosomal membranes by the sequestered copper, resulting in leakage of acid hydrolases into the cell cytoplasm. Enzyme changes are accompanied by an increase in the numbers of primary and secondary lysosomes (autophagic vacuoles), some of which contain copper (Lindquist, 1968).

The effect of copper on the uterus

Little deviation from normality was observed in the endometrium of nonpregnant copper-containing uteri up to 4 days following mating. Pronounced 
changes were observed in epithelial cells on Day 6 of gestation. The presence of numerous phagosomes and phagolysosomes containing amorphous material which stained for copper was indicative of increased activity directed towards endocytosis on the part of these organelles. In addition to the different structural forms of lysosomes, numerous myeloid bodies (lysosomes with membranous fragments) were frequently observed on Day 8 of gestation, together with necrotic nuclei and epithelial cells either in the process of being detached or lying free in the uterine lumen. Such cells were found to contain copious lysosomal and non-lysosomal $\beta$-glycerophosphatase activity. Analogous observations were made by McNatt et al. (1971), who found that administration of copper to rats resulted in a significant increase in hepatic acid p-nitrophenylphosphatase, the enzyme being stable to heat and formalin.

Some explanation is needed for the sudden burst of lysosomal activity observed during Days 6 to 8 of pregnancy. Weissman (1969) has shown that steroids alter the permeability of cells and organelles, particularly in the case of lysosomes. Smith \& Henzl (1969) noted that the treatment of spayed rabbits with oestradiol and chlormadinone produced a striking increase in the number and size of lysosomes, with the formation of autophagic vacuoles and myeloid bodies. Lysosomes in the uterine epithelial cells of the rabbit may be expected to be influenced by the oestrogen surge at the time of implantation (Hilliard \& Eaton, 1971). A change in the permeability of these lysosomes would then account for the increased uptake of copper and formation of numerous secondary lysosomes. That this is true is reflected in the increased numbers of lysosomes in epithelial cells that contain appreciable quantities of copper on Days 6 to 8, a feature that is absent in the 3-day uterus bearing the copper wire. The cytotoxic action of copper is restricted to epithelial cells and is localized to the region bearing copper wire. Although epithelial cell degeneration may be ascribed to leakage of lysosomal enzymes (as reflected in an increase in acid phosphatase reaction product, both particulate and diffuse), the rôle of these enzymes, if any, in cell detachment is not known.

Reference should be made to the significance of changes in lysosomes in the distal region of the uterine horn bearing copper wire. The presence of lysosomes in an exclusively infranuclear position on Day 6 corresponds to their situation during normal pregnancy (Abraham et al., 1970). The fact that this situation persists up to Day 10, however, suggests that the presence and attachment of a viable trophoblast (which in the present experiment was not recoverable after Day 6) may be necessary to trigger the lysosomes towards autophagy in uterine cells. Similar observations were recorded when blastocysts were injured by means of siloxanes (Abraham et al., 1973).

\section{The anti-fertility effect of copper}

Many suggestions have been advanced for the mode of action of copper in intrauterine devices and have been reviewed by Segal (1970) and Zipper et al. (1970). Some authors consider that copper is toxic to the blastocyst (Brinster \& Cross, 1972; Noesland, 1972), while others contend that the metal acts primarily on the uterus (Chang \& Tatum, 1970). Segal (1970) lists three possibilities in explaining the action of intrauterine contraceptive devices: increased uterine 
motility leading to accelerated transport of ova; biochemical changes in the endometrium; and mobilization of polymorphonuclear leucocytes. He is of the opinion that the last-mentioned factor creates a hostile environment for both spermatozoa and blastocyst and is responsible for the antifertility effect. Implicit in this conclusion is the fact that the leucocytes are rich in lysosomes, the release of whose enzymes in sufficiently high concentration in the lumen of the uterus leads to the disruption of blastocysts, as demonstrated by experiments in vitro (Parr, Schaedler \& Hirsch, 1967).

The present investigation has demonstrated that rabbit blastocysts are permeable to copper and that the metal becomes sequestered in lysosomes. Overloading of these lysosomes with copper probably would result in release of their contained enzymes and cell death. Effects of copper on the uterus were confined to the epithelial cell lysosomes and appeared to be secondary to those sustained by the blastocyst. Detachment of uterine epithelial cells rich in acid phosphatase and copper, and their eventual expulsion into the uterine lumen, could be a protective mechanism by which the rest of the uterine tissue escapes the toxic effects of the metal. This sequence of events strongly suggests that the blastocyst is the primary target through which copper exerts its antifertility effects. The relevance of these findings to other species, such as the rat and monkey, in which a powerful leucocytic response has been noted (Cuadros $\&$ Hirsch, 1972) must await investigation by the techniques reported here.

\section{ACKNOWLEDGMENTS}

The authors are grateful to Mrs Veena Shaw and Miss Joy Duci for assistance in histochemistry. This research was supported by Grant Number 2 PO100226-06 from the National Institute of Environmental Health Services, NIH, USPHS and by the National Institutes of Health Training Grant 2 TO1-ES00103-06. One of us (R.A.) is the recipient of a Research Career Development Award No. 1K04ES 70607-01.

\section{REFERENCES}

Abraham, R., Fulfs, J. C., Golberg, L. \& Goulston, F. (1973) Gytotoxic action of a mixed copolymer of phenylmethylcyclosiloxane on blastocyst lysosomes. $\mathcal{F}$. Reprod. Fert. 34, 451.

Abraham, R., Hendy, R., Dougherty, W. J., Fulfs, J. G. \& Golberg, L. (1970) Partcipation of lysosomes in early implantation in the rabbit. Exp. \& Molec. Pathol. 13, 329.

BARKa, T. \& Anderson, P. J. (1962) Histochemical methods for acid phosphatase using hexazonium pararosaniline as coupler. 7. Histochem. Cytochem. 10, 741.

Brinster, R. L. \& Gross, P. G. (1972) Effects of copper on the preimplantation mouse embryo. Nature, Lond. 238, 398.

Ghang, G. G. \& Tatum, H. J. (1970) The study of the antifertility effect of intrauterine copper. Contraception, 1, 265.

Chang, C. C., TAtum, H. J. \& Kincl, F. A. (1970) The effect of intrauterine copper and other metals on implantation in rats and hamsters. Fert. Steril. 21, 274.

Guadros, A. \& Hirsch, J. G. (1972) Copper on intrauterine devices stimulates leukocyte exudation. Science, N.Y. 175, 175.

ENDERs, A. C. (1971) The fine structure of the blastocyst. In: The Biology of the Blastocyst, p. 71. Ed. R. J. Blandau. University of Chicago Press, Chicago.

FERM, V. H. (1971) Permeability of the mammalian blastocyst to teratogens. In: The Biology of the Blastocyst, p. 291. Ed. R. J. Blandau. University of Chicago Press, Chicago. 
GOLDFISGHER, S. (1965) The localization of copper in the pericanalicular granules (lysosomes) of liver in Wilson's disease (hepatolenticular degeneration). Am. F. Path. 46, 997.

Goldfischer, S. \& Sterndirb, I. (1968) Changes in the distribution of hepatic copper in relation to the progression of Wilson's disease (hepatolenticular degeneration). Am. F. Path. 53, 883.

Gomori, G. (1952). Microscopic histochemistry: principles and practice. University of Chicago Press, Chicago.

HilliaRd, J. \& EATON, L. W., JR (1971) Estradiol-17 $\beta$, progesterone and 20 $\alpha$-hydroxypregn-4-en-3-one in rabbit ovarian venous plasma. II. From mating through implantation. Endocrinology, 89, 522.

HoLt, S. J. \& Hicks, R. M. (1961) The localization of acid phosphatase in rat liver cells as revealed by combined cytochemical staining and electronmicroscopy. F. biophys. biochem. Cytol. 11, 47.

Koenig, H. (1963) Intravital staining of lysosomes by basic dyes and metallic ions. $\mathcal{7}$. Histochem. Cytochem. 11, 120.

IeFevre, R., Coulston, F. \& Golbrra, L. (1972) Action of a copolymer of mixed phenylmethylcyclosiloxanes on reproduction in rats and rabbits. Toxicol. appl. Pharmac. 21, 29.

Lindquist, R. R. (1968) Studies on the pathogenesis of hepatolenticular degeneration. Am. F. Path. 53, 903.

MoNatt, E. N., Campbell, W. G., JR \& Galiahan, B. G. (1971) Effects of dietary copper loading on livers of rats. I. Changes in subcellular acid phosphatases and detection of an additional acid pnitrophenyl-phosphatase in the cellular supernatant during copper loading. Am. F. Path. 64, 123.

Newton, J., Elias, J. \& McEwAN, J. (1972) Intrauterine contraception using the copper-seven device. Lancet, ii, 951.

Noesland, G. (1972) Blastocytotoxic effect of copper in vitro. Contraception, 6, 281.

PARR, E. L., Schaedler, R. W. \& Hirsch, J. G. (1967) The relationship of polymorphonuclear leukocytes to infertility in uteri containing foreign bodies. F. exp. Med. 126, 523.

SEGAL, S. J. (1970) Intrauterine devices and their mechanism of action. In: Control of Human Fertility, p. 181. Eds. E. Diczfalusy and U. I. F. Borell. Nobel Symposium 15.

Smrrh, R. E. \& HENzL, M. R. (1969) Role of mucopolysaccharides and lysosomal hydrolases in endometrial regression following withdrawal of estradiol and chlormadinone acetate. I. Epithelium and stroma. Endocrinology, 85, 56.

Uzman, L. L. (1956) Histochemical localization of copper with rubeanic acid. Lab. Invest. 5, 299.

VertTy, M. A., Gambell, J. K., Reith, A. R. \& BRowN, W. J. (1967) Subcellular distribution and enzyme changes following subacute copper intoxication. Lab. Invest. 16, 580.

Weissmann, G. (1969) The effects of steroids and drugs on lysosomes. In: Lysosomes in Biology and Pathology, Part I, p. 276. Eds. J. T. Dingle and H. B. Fell. Wiley, New York.

Zipper, J., MEDEL, M., PASTENe, L., Rivera, M. \& TATUM, H. J. (1970) Human fertility control through the use of endouterine metal antagonists of trace elements. In: Control of Human Fertility, p. 199. Eds. E. Diczfalusy and U. I. F. Borell. Nobel Symposium 15.

Zipper, J., MEDeL, M. \& Prager, R. (1969) Suppression of fertility by intrauterine copper and zinc in rabbits. Am. J. Obstet. Gynec. 105, 529. 